\title{
Associação entre aditivos químicos e bacterianos na ensilagem de cana-de-açúcar
}

\section{Gustavo Rezende Siqueira ${ }^{1}$, Ricardo Andrade Reis ${ }^{2}$, Ruben Pablo Schocken-Iturrino ${ }^{3}$, Thiago Fernandes Bernardes ${ }^{4}$, Aureliano José Vieira Pires ${ }^{5}$, Marcella de Toledo Piza Roth ${ }^{6}$, Anna Paula de Toledo Piza Roth ${ }^{7}$}

\author{
${ }^{1}$ Doutorando em Zootecnia - FCAVIUNESP - Campus de Jaboticabal. Pesquisador da APTA - Pólo Regional de Desenvolvimento \\ dos Agronegócios da Alta Mogiana - Av. Rui Barbosa, s/nº, C.P. 35, CEP: 14.770-000, Colina-SP. \\ 2 Departamento de Zootecnia - FCAVIUNESP - Campus de Jaboticabal. Bolsista do CNPq. \\ ${ }^{3}$ Departamento de Microbiologia - FCAVIUNESP - Campus de Jaboticabal. Bolsista do CNPq \\ 4 Pós-doutorando, ESALQ/USP - Bolsista FAPESP. \\ 5 UESB/DTRA. Bolsista do CNPq. \\ ${ }^{6}$ Mestranda em Zootecnia - FCAVIUNESP - Campus de Jaboticabal. \\ 7 Graduanda em Agronomia - FCAVIUNESP.
}

RESUMO - Objetivou-se avaliar a ensilagem de cana-de-açúcar tratada com três aditivos químicos (uréia 1,5\%, benzoato de sódio $0,1 \%$ e hidróxido de sódio $1 \%$ ) mais o grupo controle e duas inoculações (Propionibacterium acidipropionici + Lactobacillus plantarum e Lactobacillus buchneri), em um esquema fatorial 4 x 3 com três repetições para cada tratamento. Avaliou-se o valor nutritivo da forragem antes da ensilagem, após a abertura dos silos e após a exposição aeróbia. As associações de $P$. acidipropionici ou L. buchneri com $\mathrm{NaOH}$, em comparação ao grupo controle, possibilitaram melhor preservação dos teores de MS (32,2 e 33,5 vs 27,4\%, respectivamente), FDN ( 53,4; 55,7 vs 75,3\%), FDA (39,5; 44,3 vs 48,7\%), lignina (6,6; $7,1$ vs $8,1 \%$ ) e CNF (33,8; 31,7 vs $14,9 \%)$ e, conseqüentemente, propiciaram os maiores valores de DIVMS (60,3; 63,2 vs $35,1 \%)$. Esses valores podem ser atribuídos ao controle das leveduras pelos efeitos da associação dos aditivos. A ensilagem de cana-de-açúcar requer de forma contundente a inclusão de aditivo.

Palavras-chave: estabilidade aeróbia, fermentação, inoculantes, Saccharum officinarum L., silagem, valor nutritivo

\section{Chemical and bacterial additives association on the sugar cane ensilage}

\begin{abstract}
This trial was conducted to evaluate the sugar cane silage treated with chemical additive (urea-1.5\%, sodium benzoate- $0.1 \%$, and sodium hydroxide-1.0\%), associated with control, and two bacterial inoculants (Propionibacterium acidipropionici + Lactobacillus plantarum e Lactobacillus buchneri), in a factorial scheme (4 $\mathrm{x} 3$ ), and three replications per treatment. It was evaluated the nutritive value of the sugar cane treated with different additive combinations, before and after ensilage. The association of the P. acidipropionici or L. buchneri with $\mathrm{NaOH}$, compared to the control resulted in better preservation of DM (32.2 and 33.5\%, compared to 27.4\%, respectively), and preserved the NDF (53.4; $55.7 \%$ versus 75.3\%), $\operatorname{ADF}(39.5,44.3 \%$ versus $48.7 \%$ ), lignin (6.6, 7.1\% versus $8.1 \%$ ), and NFC (33.8, 31.7\% versus $14.9 \%)$, resulting in higher true in vitro DM digestibility $(60.3,63.2 \%$ versus $35.1 \%)$. The observed values could be associated to the yeast control due to the associative additive effects. In general, it is possible to conclude that sugar cane ensilage process require an efficient additive utilization.
\end{abstract}

Key Words: aerobic stability, fermentation, inoculants, nutritive value, Saccharum officinarum L., silage

\section{Introdução}

A utilização clássica da cana-de-açúcar é na forma in natura (cortada e picada), diariamente para alimentação animal. Em grandes rebanhos, essa técnica se torna o maior empecilho para utilização desse volumoso, pois os produtores alegam dificuldades de logística operacional para realização do corte diário. Para isso, estudos sobre a ensilagem da cana-de-açúcar foram retomados a partir do final dos anos 90 por instituições brasileiras.
Segundo Nussio \& Schmidt (2004), na ensilagem da cana-de-açúcar, a obtenção de resultados técnicos e econômicos positivos depende, invariavelmente, da escolha correta do aditivo a ser usado. Nesse sentido, resultados de estudos com vários aditivos químicos e bacterianos são encontrados na literatura na ensilagem de culturas como milho e sorgo.

Adição de uréia na ensilagem baseia-se na transformação dessa uréia em $\mathrm{NH}_{3}$, que reage com água formando hidróxido de amônia, elevando o pH e atuando sobre o 
metabolismo de microrganismos indesejáveis, principalmente leveduras, ressaltando-se que a aplicação de amônia está associada a dificuldades operacionais (Kung Jr. et al., 2003). A utilização de uréia na ensilagem de cana-de-açúcar foi estudada por Alvarez \& Preston (1976), que avaliaram a atuação de uréia no controle das perdas de açúcares representados pelo grau Brix (sacarose, açúcares redutores e não-açúcares em \% do caldo). A dose de 1,02\% de uréia propiciou menor redução no teor de açúcares (9\%), enquanto, na silagem controle, a perda foi de $40 \%$.

O hidróxido de sódio é um aditivo muito utilizado para aumentar a digestibilidade de palhadas (McDonald et al., 1991). Nieblas et al. (1982) recomendaram a utilização do $\mathrm{NaOH}$ na ensilagem da cana-de-açúcar, pois, segundo os autores, esse álcali foi capaz de alterar a fer-mentação basicamente alcoólica para fermentação predominantemente lática. Segundo os autores, esse aumento, no caso da silagem de cana-de-açúcar, resulta da elevação do pH inicial, que estimularia a atuação das bactérias acidoláticas.

Woolford (1975) atribui ao benzoato de sódio propriedades antimicrobianas e eficiente efeito na redução do pH. Segundo esse autor, a concentração de benzoato de sódio necessária para inibição de leveduras reduz à medida que o $\mathrm{pH}$ decresce.

O gênero Propionibacterium é caracterizado pela produção dos ácidos acético e propiônico durante a fermentação de carboidratos solúveis e ácido lático (McDonald et al., 1991). Filya et al. (2004) estudaram a inoculação do Propionibacterium acidipropionici associado ou não ao Lactobacillus plantarum na fermentação e na estabilidade aeróbia de silagens de trigo, de sorgo e de milho e observaram que o $P$. acidipropionici foi eficiente no controle do desenvolvimento de leveduras e fungos filamentosos nas fases de fermentação e de estabilidade aeróbia. A utilização de L. plantarum de forma isolada seria benéfica quanto ao período de fermentação (Kung et al., 2003), enquanto as bactérias do gênero Propionibacterium tiveram efeito pronunciado sobre a estabilidade aeróbia, em virtude do controle de leveduras e fungos.

Ranjit \& Kung Jr. (2000) estudaram a inoculação de Lactobacillus buchneri na ensilagem de milho e avaliaram as características fermentativas e a estabilidade aeróbia dessas silagens. A inoculação com L. buchneri reduziu a população de leveduras na abertura dos silos de 6,05 (controle) para 2,02 log ufc/g de silagem, como resultado da maior concentração de ácido acético 3,6 (inoculada) vs 1,82\% nas silagens não-inoculadas. Em virtude da menor população de leveduras, o pH das silagens tratadas com
L. buchneri sofreu menores elevações, reduzidas perdas de carboidratos solúveis e de ácido lático e maior tempo para elevação da temperatura.

Uma nova linha de pesquisa tem sido a associação de microrganismos a aditivos químicos visando melhorar a eficiência no controle das fases de fermentação e estabilidade aeróbia. Neste estudo, avaliaram-se as alterações químicas durante a fermentação e a exposição aeróbia de silagens de cana-de-açúcar tratadas com aditivos químicos (uréia, benzoato de sódio e $\mathrm{NaOH}$ ) associados ou não a inoculantes $(P$. acidipropionici $+L$. plantarum $\mathrm{e}$ L. buchneri).

\section{Material e Métodos}

A cana-de-açúcar (Saccharum officinarum L.) utilizada foi o cultivar SP70-1143, proveniente da Usina Andrade Açúcar e Álcool, localizada no município de Pitangueiras, distrito de Ibitiuva-SP. A adubação foi realizada com $400 \mathrm{~kg} /$ ha do formulado 20-05-20 e o controle de invasoras foi feito após o terceiro corte com o herbicida Platô. A colheita manual foi realizada no mês de outubro de 2003, quando a cana-de-açúcar apresentava-se apta para o quarto corte. A produção estimada foi de $80 \mathrm{t} \mathrm{MV} / \mathrm{ha}$ aos 15 meses de crescimento vegetativo e com 16\% de pol (sacarose -\% da cana-de-açúcar).

A forragem foi transportada até as dependências da UNESP-Jaboticabal e, no dia posterior ao corte, foi processada em picadeira estacionária em partículas de 1 a $3 \mathrm{~cm}$, sem sofrer despalhamento.

Foram avaliados os seguintes tratamentos: sem inoculante e sem aditivos químicos; sem inoculante e com 1,5\% de uréia; sem inoculante com $0,1 \%$ de benzoato de sódio; sem inoculante e com $1 \%$ de hidróxido de sódio; $P$. acidipropionici $+L$. plantarum sem aditivo químico; $P$. acidipropionici + L. plantarum com $1,5 \%$ de uréia; $P$. acidipropionici $+L$. plantarum com $0,1 \%$ de benzoato de sódio; $P$. acidipropionici + L.plantarum com $1 \%$ de hidróxido de sódio; L. buchneri sem aditivo químico; L. buchneri com 1,5\% de uréia; L. buchneri com $0,1 \%$ de benzoato de sódio; L. buchneri com 1\% de hidróxido de sódio, em um esquema fatorial $3 \times 4$, em um total de 12 tratamentos com três repetições.

Os microrganismos Propionibacterium acidipropionici (Cepa MS 01) e Lactobacillus plantarum (Cepa MA 18/50) são encontrados no inoculante comercial Propiolact ${ }^{\circledR}$ (PROP) e o microrganismo Lactobacillus buchneri (Cepa NCIMB 40788), no inoculante comercial LalsilCana ${ }^{\circledR}$ (BUCH). O P. acidipropionici 
e o L. plantarum foram aplicados na dose de $1,5 \times 10^{5} \mathrm{ufc} / \mathrm{g}$ de forragem e o L. buchneri, na dose de $5 \times 10^{4} \mathrm{ufc} / \mathrm{g}$ de forragem. A uréia foi diluída em água e aplicada em solução de $35 \mathrm{~L} / \mathrm{t}$ de forragem, o benzoato de sódio, por meio de solução de $15 \mathrm{~L} / \mathrm{t}$, e o hidróxido de sódio $(\mathrm{NaOH})$, em solução de $33,3 \%$. Nos tratamentos com associação entre inoculante e aditivo químico, a aplicação foi realizada separadamente; primeiro foi pulverizado o inoculante e logo depois o aditivo químico.

Como silos experimentais foram utilizados tubos de PVC (50 cm de altura e $10 \mathrm{~cm}$ de diâmetro) com tampas com válvulas de Bunsen para permitir o escape do gás.

A ensilagem foi realizada com auxílio de bastões de ferro, objetivando obter densidade de $650 \mathrm{~kg}$ de forragem $/ \mathrm{m}^{3}$. Para isso, determinou-se o volume de cada silo experimental e pesou-se a quantidade de forragem necessária para obter a densidade desejada. Após a compactação da forragem, os silos foram vedados com fita adesiva, pesados e armazenados. Decorridos 60 dias de fermentação, os silos foram novamente pesados e abertos.

Antes da ensilagem, após a aplicação dos inoculantes e/ou aditivos, a forragem foi amostrada três vezes em cada tratamento. Cada amostra foi fragmentada ainda em duas subamostras: uma foi destinada à quantificação do pH, segundo Silva \& Queiroz (2002), e a outra foi pesada e conservada em estufa de ventilação forçada a $55^{\circ} \mathrm{C}$ durante 72 horas. Procedimentos idênticos foram aplicados às amostras após a abertura dos silos. As amostras mantidas em estufa foram novamente pesadas, trituradas em moinho de faca até que o tamanho das partículas atingissem menos de $1 \mathrm{~mm}$ e armazenadas em potes de plástico.

Os teores de MS, PB, NIDN/N e EE foram determinados segundo metodologia descrita por Silva \& Queiroz (2002) e os de FDN e FDA foram avaliados pelo método seqüencial, conforme técnicas descritas por Van Soest (1991). Os teores de lignina foram calculados pela diferença entre FDA e celulose e os de celulose foram determinados utilizando-se ácido sulfúrico a 72\% (Van Soest, 1994). Os carboidratos não-fibrosos (CNF) foram calculados pela expressão CNF $=100-($ FDN + MM + PB + EE $)$ e a DIVMS foi determinada pelo método de Tilley \& Terry, descrito por Silva \& Queiroz (2002).

Determinou-se também a variação dos teores de MS (VMS), calculada como a diferença entre as porcentagens de MS obtidas no momento da ensilagem e na abertura, expressa em módulo.

Determinaram-se as recuperações de CNF e MS digestível verdadeira pela seguinte equação:

$$
\operatorname{Rec}=(\mathrm{MSF} * \% \mathrm{Ff}) /(\mathrm{MSI} * \% \mathrm{Fi}) * 100
$$

em que Rec: recuperação da fração X (\% da fração X); MSF: MS no momento da abertura (quantidade de forragem (kg) *\% MS); \%Ff: porcentagem da fração X no momento da abertura; MSI: MS ensilada (quantidade de forragem (kg) *\% MS); \% Fi: porcentagem da fração X no momento da ensilagem.

Após a abertura dos silos, amostras foram colocadas em baldes plásticos e armazenadas em câmara climática a $25 \pm 1^{\circ} \mathrm{C}$ para avaliação da estabilidade aeróbia. Decorridos cinco dias de exposição aeróbia, os baldes foram amostrados para realização das mesmas análises feitas nas amostras de silagem após a abertura.

O delineamento experimental utilizado foi o inteiramente casualizado, em esquema fatorial ( $3 \times 4)$ com três repetições, considerando os fatores: inoculação (controle, $P$. acidipropionici $+L$. plantarum e $L$. buchneri) e aditivos químicos (controle, uréia, benzoato de sódio e hidróxido de sódio).

Os dados foram analisados estatisticamente pelos procedimentos de análise de variância e as médias comparadas pelo teste Tukey a 5\% de significância, utilizando o programa de análises estatísticas SAS.

\section{Resultados e Discussão}

Na Tabela 1 estão relacionados os valores de pH antes da ensilagem e após a abertura dos silos. Antes da ensilagem, as forragens do grupo controle tiveram maiores valores de $\mathrm{pH}(\mathrm{P}<0,05)$, porém, biologicamente, essa diferença $(0,1$ unidades de $\mathrm{pH}$ ) pode ser considerada insignificante. No entanto, as forragens tratadas com $\mathrm{NaOH}$, apresentaram $\mathrm{pH}$ superior ao das demais, pois o $\mathrm{NaOH}$ é considerado substância alcalinizante.

Após a abertura, as silagens tratadas com uréia ou com $\mathrm{NaOH}$, independentemente do inoculante utilizado, apresentaram os maiores valores de $\mathrm{pH}$. Com relação à uréia, a elevação do $\mathrm{pH}$ pode ser atribuída ao aumento da concentração de amônia nessas silagens. Kung Jr. et al. (2003), em revisão sobre aditivos para ensilagem, concluíram que forragens tratadas com uréia e com eficiente transformação dessa uréia em amônia resultam em silagens com $\mathrm{pH}$ superior ao das não-tratadas.

Outro fato importante é a tendência de menores valores de $\mathrm{pH}$ nas silagens inoculadas com BUCH, seguidas das inoculadas com PROP, e de maiores valores na silagem controle. No entanto, nas silagens tratadas com uréia, essa tendência foi inversa, o que pode estar relacionado à possível eficiência de transformação da uréia em amônia pelos microrganismos, pois a amônia é uma substância com poder alcalinizante e, conseqüentemente, dificulta a redução do pH. 
O tratamento da cana-de-açúcar com $\mathrm{NaOH}$ propiciou a obtenção de silagens com valores de $\mathrm{pH}$ superiores (Tabela 1). O pH final da silagem é resultado da extensão da fermentação, principalmente a realizada por microrganismos homofermentativos. Em silagens com alta capacidade tamponante, característica de silagens tratadas com $\mathrm{NaOH}$, a quantidade de moles de ácido lático necessária para reduzir o pH em uma unidade é maior que a necessária para silagens com baixa capacidade tamponante. Além disso, os ácidos orgânicos produzidos durante a fermentação encontram-se dissociados, elevando a capacidade tamponante, como verificado por Evangelista et al. (2003) em silagens de cana-de-açúcar em diferentes tempos de fermentação. Esses autores observaram que, à medida que avançava o tempo de estocagem, a capacidade tamponante das silagens elevou de 1,2 (dia da ensilagem) para 17 e.mg de $\mathrm{HCl} / 100 \mathrm{~g}$ MS (60 dias de fermentação), comprovando que, a cada dia de fermentação, torna-se mais difícil a redução do pH.
Os teores de MS da cana-de-açúcar (Tabela 2) podem ser considerados adequados para ensilagem dessa forragem. As variações observadas entre os teores de MS antes da ensilagem foram ocasionadas pelo tempo do corte até a confecção do silo. Entretanto, após a abertura, as diferenças entre os teores de MS das silagens possivelmente decorreram das perdas de MS durante a fermentação. Alli et al. (1983), avaliando o perfil de fermentação de silagens de cana-deaçúcar tratadas ou não com hidróxido de amônia, observaram redução de 4 e 1 unidades percentuais de MS nas silagens controle e tratadas, respectivamente. Evangelista et al. (2003) verificaram redução de 36,0 para 25,3\% MS em dez dias de fermentação. Nos dois trabalhos, a redução da MS pode ser atribuída ao consumo de carboidratos solúveis durante a fermentação. Portanto, é imporante avaliar a variação entre os teores de MS antes da ensilagem e após a abertura do silo, pois essa variação constitui indicativo de perda de MS durante a fermentação.

Tabela 1 - Valores de pH, antes da ensilagem e após a abertura dos silos, da cana-de-açúcar tratada com aditivos químicos e bacterianos Table 1 - Values of $\mathrm{pH}$ before ensilage and after opening of the silos of the sugar cane treated with chemical additives or inoculants

\begin{tabular}{|c|c|c|c|c|c|c|c|c|}
\hline \multirow[t]{2}{*}{$\begin{array}{l}\text { Tratamento } \\
\text { Treatment }\end{array}$} & \multicolumn{4}{|c|}{$\begin{array}{c}\text { Ensilagem } \\
\text { Ensilage }\end{array}$} & \multicolumn{4}{|c|}{$\begin{array}{l}\text { Abertura } \\
\text { Silo opening }\end{array}$} \\
\hline & $\begin{array}{c}\text { Controle } \\
\text { Control }\end{array}$ & $\mathrm{PROP}^{2}$ & $\mathrm{BUCH}^{3}$ & $\begin{array}{l}\text { Média } \\
\text { Mean }\end{array}$ & $\begin{array}{c}\text { Controle } \\
\text { Control }\end{array}$ & PROP $^{2}$ & $\mathrm{BUCH}^{3}$ & $\begin{array}{l}\text { Média } \\
\text { Mean }\end{array}$ \\
\hline Controle (Control) & 5,9 & 5,6 & 5,7 & $5,8 b$ & $3,7 \mathrm{Ac}$ & $3,5 \mathrm{Bc}$ & $3,4 \mathrm{Bb}$ & $3,6 c$ \\
\hline Uréia (Urea) & 5,8 & 5,8 & 5,7 & $5,8 b$ & $4,2 \mathrm{Bb}$ & $4,3 \mathrm{Bb}$ & 4,6Aa & $4,4 \mathrm{~b}$ \\
\hline Benzoato (Benzoate) & 6,0 & 5,7 & 5,7 & $5,8 b$ & $3,7 \mathrm{Ac}$ & $3,6 \mathrm{Ac}$ & $3,5 \mathrm{Bb}$ & $3,6 \mathrm{c}$ \\
\hline $\mathrm{NaOH}$ & 11,7 & 11,6 & 11,6 & $11,6 a$ & $4,6 \mathrm{Aa}$ & $4,6 \mathrm{Aa}$ & $4,5 \mathrm{Ba}$ & $4,6 a$ \\
\hline Média (Mean) & $7,3 \mathrm{~A}$ & $7,2 \mathrm{~B}$ & $7,2 \mathrm{~B}$ & 7,2 & $4,1 \mathrm{~A}$ & $4,0 \mathrm{~B}$ & $4,0 \mathrm{~B}$ & 4,0 \\
\hline CV (\%) & & & & 1,71 & & & & 1,40 \\
\hline
\end{tabular}

Médias seguidas da mesma letra, maiúscula na linha e minúscula na coluna, não diferem $(P<0,05)$ pelo teste Tukey.

Means followed by the same small letter, capital in a row and small in the column, are similar $(P>0.05)$ by Tukey test.

${ }^{1}$ 1,5\% de uréia; $0,1 \%$ de benzoato de sódio e $1 \%$ de hidróxido de sódio em relação à matéria verde.

$1.5 \%$ of urea; $0.1 \%$ of sodium benzoate, and $1 \%$ of sodium hidroxide expressed in a fresh basis.

2 Propionibacterium acidipropionici + Lactobacillus plantarum; ${ }^{3}$ Lactobacillus buchneri.

Tabela 2 - Teores de MS (\%), antes da ensilagem e após abertura dos silos, da cana-de-açúcar tratada com aditivos químicos e bacterianos

Table 2 - DM concentration, before ensilage and after opening of the silos, of the sugar cane treated with chemical additives or inoculants

\begin{tabular}{|c|c|c|c|c|c|c|c|c|}
\hline \multirow[t]{2}{*}{$\begin{array}{l}\text { Tratamento }{ }^{1} \\
\text { Treatment }\end{array}$} & \multicolumn{4}{|c|}{$\begin{array}{c}\text { Ensilagem } \\
\text { Ensilage }\end{array}$} & \multicolumn{4}{|c|}{$\begin{array}{c}\text { Abertura } \\
\text { Silo opening }\end{array}$} \\
\hline & $\begin{array}{c}\text { Controle } \\
\text { Control }\end{array}$ & $\mathrm{PROP}^{2}$ & $\mathrm{BUCH}^{3}$ & $\begin{array}{l}\text { Média } \\
\text { Mean }\end{array}$ & $\begin{array}{c}\text { Controle } \\
\text { Control }\end{array}$ & $\mathrm{PROP}^{2}$ & $\mathrm{BUCH}^{3}$ & $\begin{array}{c}\text { Média } \\
\text { Mean }\end{array}$ \\
\hline Controle (Control) & $35,2 \mathrm{Ab}$ & $35,6 \mathrm{Aa}$ & $35,1 \mathrm{Aa}$ & $35,3 a b$ & $27,4 \mathrm{Bb}$ & $28,0 \mathrm{Bd}$ & 31,9Ac & $29,1 \mathrm{c}$ \\
\hline Uréia (Urea) & $35,8 \mathrm{Aab}$ & $34,0 \mathrm{Bb}$ & $34,6 \mathrm{Ba}$ & $34,8 b$ & $29,1 \mathrm{Ba}$ & $29,4 \mathrm{Bc}$ & $31,2 \mathrm{Ac}$ & $29,9 b$ \\
\hline Benzoato (Benzoate) & $35,2 \mathrm{Ab}$ & 35,1Aab & $35,5 \mathrm{Aa}$ & $35,3 a b$ & $29,4 \mathrm{Ca}$ & $30,6 \mathrm{Bb}$ & $34,7 \mathrm{Aa}$ & 31,6a \\
\hline $\mathrm{NaOH}$ & $36,8 \mathrm{Aa}$ & $36,2 \mathrm{Aa}$ & $34,9 \mathrm{Ba}$ & $35,9 a$ & $29,1 \mathrm{Ca}$ & $32,2 \mathrm{Ba}$ & $33,5 \mathrm{Ab}$ & $31,6 a$ \\
\hline Média (Mean) & $35,7 \mathrm{~A}$ & $35,2 \mathrm{AB}$ & $35,0 \mathrm{~B}$ & 35,3 & $28,7 \mathrm{C}$ & $30,1 \mathrm{~B}$ & $32,8 \mathrm{~A}$ & 30,5 \\
\hline CV (\%) & & & & 1,70 & & & & 1,49 \\
\hline
\end{tabular}

Médias seguidas da mesma letra, maiúscula na linha e minúscula na coluna, não diferem $(P<0,05)$ pelo teste Tukey.

Means followed by the same small letter, capital in a row and small in the column, are similar $(P>0.05)$ by Tukey test.

1 1,5\% de uréia; $0,1 \%$ de benzoato de sódio e $1 \%$ de hidróxido de sódio em relação à matéria verde.

1 1.5\% of urea; $0.1 \%$ of sodium benzoate, and $1 \%$ of sodium hidroxide expressed in a fresh basis.

2 Propionibacterium acidipropionici + Lactobacillus plantarum; ${ }^{3}$ Lactobacillus buchneri. 
Os teores de PB antes da ensilagem (Tabela 3) diferiram significativamente apenas quando a forragem foi tratada com uréia, pois esse é um aditivo com alta concentração de nitrogênio (45\%). Após a abertura, foi significativo o efeito da inoculação sobre o teor da PB nas silagens tratadas com uréia.

À exceção das silagens que possivelmente perderam nitrogênio na forma de amônia, o teor de PB foi numericamente maior após a abertura que antes da ensilagem. Provavelmente, não houve síntese de proteína, e sim efeito da concentração dessa fração sobre as perdas de açúcares solúveis.

Os teores de NIDN das silagens tratadas com uréia foram inferiores aos obtidos com os demais aditivos químicos, independentemente da inoculação, tanto antes da ensilagem como após a abertura. Essa inferioridade pode ter resultado da inclusão nessas silagens de nitrogênio solúvel (uréia), diluindo, assim, o NIDN. Rocha Jr. et al. (2003) encontraram valor de 5,66\% de NIDN na cana-de-açúcar tratada com $1 \%$ de uréia.

Na Tabela 4 são apresentados os teores de FDN da cana-de-açúcar antes da ensilagem e após a abertura dos silos. Na ensilagem, verificou-se diferença estatística entre as inoculações $(\mathrm{P}<0,05)$, porém, numericamente, essas diferenças podem ser consideradas pequenas (uma unidade percentual). Contudo, quando a cana-de-açúcar foi tratada com $\mathrm{NaOH}$, houve redução no teor de FDN em todas as forragens. O efeito de hidrólise alcalina sobre a fibra ocorre de modo rápido e, considerando que durante o processo de secagem em estufa essa reação ainda aconteça, justifica-se a redução da fração FDN. Pires et al. (2006) avaliaram doses de $\mathrm{NaOH}(0,2,5,5$ e 7,5\% da MS) na estocagem do bagaço de cana-de-açúcar durante 1, 3, 5 e 7 dias e não constataram efeito do tempo sobre os teores de FDN, FDA e lignina, no entanto, notaram efeito das doses em todas as variáveis anteriormente citadas, comprovando a rápida atuação do hidróxido de sódio.

Após a abertura dos silos, verificou-se elevação nos teores de FDN em todas as silagens, o que, possivelmente, resultou das perdas de CNF (Tabela 4). Evangelista et al. (2003), avaliando o perfil de fermentação na ensilagem de cana-de-açúcar, observaram elevação de 55,6 para 75,6\% no teor de FDN após 50 dias de fermentação. Castro Neto et al. (2003) também constataram elevação de 55,1 para 72,9\% nos teores de FDN na cana-de-açúcar ensilada sem aditivos. A elevação do teor de FDN durante a ensilagem da cana-deaçúcar parece ser comum nos estudos em silos experimentais.

Após a ensilagem, verificou-se elevação dos teores de FDA em todas as silagens. Alli et al. (1983) observaram elevação de 28,3 para $37,7 \%$ nos teores de FDA na ensilagem da cana-de-açúcar após 42 dias de fermentação, o que pode ser atribuído ao consumo de CNF.

Os teores de CNF (Tabela 5) antes da ensilagem diferiram $(\mathrm{P}<0,05)$ entre os aditivos químicos nas silagens tratadas

Tabela 3 - Teores de PB (PB\%) e NIDN (\% N-total), antes da ensilagem e após a abertura dos silos, na cana-de-açúcar tratada ou não com aditivos químicos e bacterianos

Table 3 - Concentrations of $C P(C P \%)$ and N-NDF, before ensilage and after opening the silos, of the sugar cane treated or not with chemical additives or inoculants

\begin{tabular}{|c|c|c|c|c|c|c|c|c|}
\hline \multirow[t]{2}{*}{$\begin{array}{l}\text { Tratamento } \\
\text { Treatment }\end{array}$} & \multicolumn{4}{|c|}{$\begin{array}{l}\text { Ensilagem } \\
\text { Ensilage }\end{array}$} & \multicolumn{4}{|c|}{$\begin{array}{l}\text { Abertura } \\
\text { Silo opening }\end{array}$} \\
\hline & $\begin{array}{c}\text { Controle } \\
\text { Control }\end{array}$ & $\mathrm{PROP}^{2}$ & $\mathrm{BUCH}^{3}$ & $\begin{array}{l}\text { Média } \\
\text { Mean }\end{array}$ & $\begin{array}{c}\text { Controle } \\
\text { Control }\end{array}$ & $\mathrm{PROP}^{2}$ & $\mathrm{BUCH}^{3}$ & $\begin{array}{l}\text { Média } \\
\text { Mean }\end{array}$ \\
\hline
\end{tabular}

$\mathrm{PB}(\%)(C P, \%)$

Controle (Control)

Uréia (Urea)

Benzoato (Benzoate)

$\mathrm{NaOH}$

Média (Mean)

CV $(\%)$

$\begin{array}{rrr}1,5 & 1,4 & 1,5 \\ 12,4 & 12,8 & 12,6 \\ 1,3 & 1,3 & 1,5 \\ 1,4 & 1,2 & 1,1 \\ 4,2 \mathrm{~A} & 4,2 \mathrm{~A} & 4,2 \mathrm{~A}\end{array}$

1,5

2,6

1,1

$4,2 \mathrm{~A}$

$1,5 b$
$12,6 a$
$1,4 b$
$1,3 b$
4,2
8,83

$1,7 \mathrm{Ab}$

13,9Aa

$1,8 \mathrm{Ab}$

$2,0 \mathrm{Ab}$

$4,9 \mathrm{~A}$ 8,83

$2,0 \mathrm{Ab}$
$11,1 \mathrm{Ba}$
$1,9 \mathrm{Ab}$
$1,5 \mathrm{Ab}$
$4,1 \mathrm{~B}$

NIDN (\% do N-total) (N-NDF, \%)

Controle (Control)

Uréia (Urea)

Benzoato (Benzoate)

$\mathrm{NaOH}$

Média (Mean)

CV (\%)

$\begin{array}{lccc}45,4 \mathrm{Bb} & 50,0 \mathrm{Bb} & 55,7 \mathrm{Aa} & 50,4 \mathrm{~b} \\ 5,3 \mathrm{Ac} & 8,3 \mathrm{Ac} & 6,7 \mathrm{Ab} & 6,8 \mathrm{c} \\ 47,3 \mathrm{Bab} & 47,5 \mathrm{Bb} & 53,6 \mathrm{Aa} & 49,5 \mathrm{~b} \\ 51,6 \mathrm{Ba} & 60,3 \mathrm{Aa} & 56,2 \mathrm{ABa} & 56,0 \mathrm{a} \\ 37,4 \mathrm{~B} & 41,5 \mathrm{~A} & 43,1 \mathrm{~A} & 40,6 \\ & & & 5,64\end{array}$

$55,8 \mathrm{Aa}$

$8,7 \mathrm{Ac}$

$37,5 \mathrm{Ab}$

$58,4 \mathrm{Ba}$

$40,1 \mathrm{~A}$

$$
\begin{aligned}
& 42,4 \mathrm{Bb} \\
& 10,6 \mathrm{Ad} \\
& 31,8 \mathrm{Bc} \\
& 63,2 \mathrm{Aa} \\
& 37,0 \mathrm{~B}
\end{aligned}
$$

$1,7 \mathrm{Ab}$

$8,5 \mathrm{Ca}$

$1,8 \mathrm{Ab}$

$1,5 \mathrm{Ab}$

$3,4 \mathrm{C}$

$\begin{array}{lc}35,1 \mathrm{Cb} & 44,4 \mathrm{~b} \\ 10,8 \mathrm{Ac} & 10,0 \mathrm{~d} \\ 30,9 \mathrm{Bb} & 33,4 \mathrm{c} \\ 62,3 \mathrm{ABa} & 61,3 \mathrm{a} \\ 34,8 \mathrm{C} & 37,3 \\ & 5,38\end{array}$

Médias seguidas da mesma letra, maiúscula na linha e minúscula na coluna, não diferem $(P<0,05)$ pelo teste Tukey.

Means followed by the same small letter, capital in a row and small in the column, are similar $(P>0.05)$ by Tukey test.

${ }_{1}^{1}, 5 \%$ de uréia; $0,1 \%$ de benzoato de sódio e $1 \%$ de hidróxido de sódio em relação à matéria verde.

${ }^{1} 1.5 \%$ of urea; $0.1 \%$ of sodium benzoate, and $1 \%$ of sodium hidroxide expressed in a fresh basis.

2 Propionibacterium acidipropionici + Lactobacillus plantarum; ${ }^{3}$ Lactobacillus buchneri. 
Tabela 4 - Teores de FDN, FDA e lignina (\%), antes da ensilagem e após a abertura dos silos, da cana-de-açúcar tratada ou não com aditivos químicos e bacterianos

Table 4 - Values of NDF, ADF, and lignin, before ensilage and after opening of the silos, of the sugar cane treated or not with chemical additives or inoculants

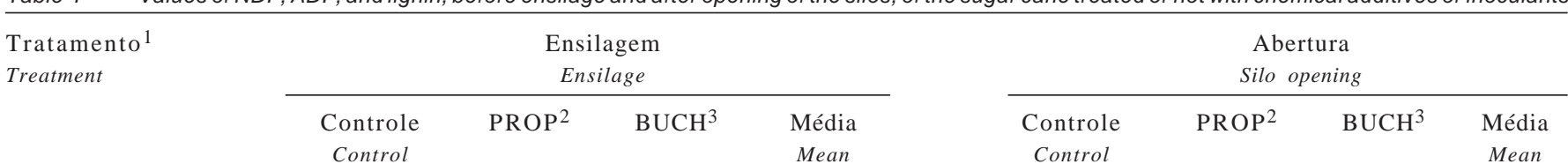

FDN $(N D F)$

Controle (Control)

Uréia (Urea)

Benzoato (Benzoate)

$\mathrm{NaOH}$

Média (Mean)

CV $(\%)$

$\begin{array}{lll}52,1 \mathrm{Ba} & 52,3 \mathrm{Bb} & 55,1 \mathrm{Aa} \\ 51,9 \mathrm{Ba} & 55,2 \mathrm{Aa} & 53,1 \mathrm{Ba} \\ 51,7 \mathrm{ABa} & 50,4 \mathrm{Ba} & 53,0 \mathrm{Aa} \\ 47,6 \mathrm{Ab} & 46,8 \mathrm{Ac} & 46,0 \mathrm{Ab} \\ 50,8 \mathrm{~A} & 51,2 \mathrm{~A} & 51,8 \mathrm{~A}\end{array}$

$53,1 \mathrm{a}$
$53,4 \mathrm{a}$
$51,7 \mathrm{~b}$
$46,8 \mathrm{c}$
51,3
1,82

75,3 Aa
72,2 Ab
70,4Ab
59,2 Ac
$69,3 \mathrm{~A}$

$\begin{array}{lll}74,3 \mathrm{Aa} & 66,9 \mathrm{Ba} & 72,2 \mathrm{a} \\ 70,5 \mathrm{Ab} & 67,5 \mathrm{Ba} & 70,1 \mathrm{~b} \\ 69,2 \mathrm{Ab} & 61,7 \mathrm{Bb} & 67,1 \mathrm{c} \\ 53,4 \mathrm{Bc} & 55,7 \mathrm{Bc} & 56,1 \mathrm{~d} \\ 66,8 \mathrm{~B} & 63,0 \mathrm{C} & 66,4 \\ & & 1,89\end{array}$

FDA $(A D F)$

Controle (Control)
Uréia (Urea)
Benzoato (Benzoate)
$\mathrm{NaOH}$
Média (Mean)
$\mathrm{CV}(\%)$

\begin{tabular}{|c|c|c|c|}
\hline $34,8 \mathrm{Aa}$ & 35,6 Aab & $35,0 \mathrm{Aa}$ & $35,1 \mathrm{a}$ \\
\hline $35,2 \mathrm{ABa}$ & $36,1 \mathrm{Aa}$ & 33,2Bab & $34,8 \mathrm{ab}$ \\
\hline $35,0 \mathrm{Aa}$ & 34,4 Aab & $31,2 \mathrm{Bbc}$ & $33,5 \mathrm{bc}$ \\
\hline $35,9 \mathrm{Aa}$ & $33,4 \mathrm{Bb}$ & $30,0 \mathrm{Cc}$ & $33,1 \mathrm{c}$ \\
\hline $35,2 \mathrm{~A}$ & $34,9 \mathrm{~A}$ & $32,3 \mathrm{~B}$ & $\begin{array}{c}34,1 \\
3,25\end{array}$ \\
\hline
\end{tabular}

$48,7 \mathrm{Aa}$
$45,8 \mathrm{ABb}$
$44,7 \mathrm{Bb}$
$41,1 \mathrm{Bc}$
$45,1 \mathrm{~B}$

$\begin{array}{lll}48,2 \mathrm{ABa} & 45,6 \mathrm{Bb} & 47,5 \mathrm{a} \\ 43,7 \mathrm{Bb} & 46,6 \mathrm{Ab} & 45,3 \mathrm{~b} \\ 47,4 \mathrm{Aa} & 49,7 \mathrm{Aa} & 47,3 \mathrm{a} \\ 39,5 \mathrm{Bc} & 44,3 \mathrm{Ab} & 41,6 \mathrm{c} \\ 44,7 \mathrm{~B} & 46,5 \mathrm{~A} & 45,4 \\ & & 2,85\end{array}$

Lignina (Lignin)

\begin{tabular}{|c|c|c|c|c|c|c|c|c|}
\hline Controle (Control) & $6,9 \mathrm{Bb}$ & 8,7Aab & 7,7ABb & $7,8 a b$ & $8,1 \mathrm{Ba}$ & $9,8 \mathrm{Aa}$ & $8,2 \mathrm{Ba}$ & $8,7 a$ \\
\hline Uréia (Urea) & $6,6 \mathrm{Bb}$ & $9,4 \mathrm{Aa}$ & $10,2 \mathrm{Aa}$ & $8,7 \mathrm{a}$ & 7,3А & $7,3 \mathrm{Ab}$ & $8,1 \mathrm{Aa}$ & $7,6 \mathrm{bc}$ \\
\hline $\mathrm{NaOH}$ & $8,0 \mathrm{Aab}$ & 7,6Aab & $6,9 \mathrm{Ab}$ & $7,5 b$ & $7,1 \mathrm{Aa}$ & $6,6 \mathrm{Ab}$ & 7,1 Aa & $6,9 \mathrm{c}$ \\
\hline CV (\%) & & & & 11,11 & & & & 7,90 \\
\hline
\end{tabular}

Médias seguidas da mesma letra, maiúscula na linha e minúscula na coluna, não diferem $(P<0,05)$ pelo teste Tukey.

Means followed by the same small letter, capital in a row and small in the column, are similar $(P>0.05)$ by Tukey test.

1 1,5\% de uréia; $0,1 \%$ de benzoato de sódio e $1 \%$ de hidróxido de sódio em relação à matéria verde.

$1.5 \%$ of urea; $0.1 \%$ of sodium benzoate, and $1 \%$ of sodium hidroxide expressed in a fresh basis.

2 Propionibacterium acidipropionici + Lactobacillus plantarum; ${ }^{3}$ Lactobacillus buchneri.

com uréia, como conseqüência da correção de nitrogênio pelo fator de 6,25. Portanto, houve subestimação desses teores de CNF. Entre as silagens tratadas com inoculantes, houve diferença $(\mathrm{P}<0,05)$, porém, biologicamente essa diferença pode ser considerada insignificante, pois variou em 0,8 unidades percentuais de uma fração com média de $38,1 \%$, o pode estar associado ao baixo coeficiente de variação (3,2\%).

Após a abertura dos silos, as silagens inoculadas com BUCH apresentaram os maiores valores de CNF e não diferiram apenas daquelas inoculadas com PROP e tratadas com $\mathrm{NaOH}$. No entanto, houve redução numérica dos teores de CNF em todas as silagens após a abertura. Alli et al. (1983) observaram redução de 47,0\% para 1,02 e 25\% nos carboidratos solúveis nas silagens controle e tratadas com $\mathrm{NH}_{3}$ após 21 dias de fermentação. Neste mesmo trabalho, após sete dias de fermentação nas silagens controle, o teor de carboidratos solúveis reduziu para $3,2 \%$, comprovando que, na ensilagem de cana-de-açúcar, a intensidade de transformações durante os primeiros dias de ensilagem é alta. Ressalta-se que a avaliação pelos CNF deve ser realizada com critério e não associada de forma direta aos carboidratos solúveis, pois, na estimativa dos CNF, computa-se a presença de outros compostos como ácidos orgânicos e qualquer substância que não for determinada pelas análises de PB, FDN, EE e cinzas. A determinação dos carboidratos solúveis é realizada por análise química. Nesse sentido, busca-se com a determinação dos CNF uma inferência das transformações ocorridas na fração de carboidratos.

As silagens tratadas com $\mathrm{NaOH}$, independentemente da inoculação, apresentaram os maiores valores de DIVMS, pois, como relatado sobre a FDN, provavelmente ocorreu hidrólise alcalina durante o processo de secagem. Pires et al. (2004) não observaram efeito do tempo de estocagem (1, 3, 5 e 7 dias) sobre a digestibilidade do bagaço de canade-açúcar tratado com $\mathrm{NaOH}$, mas verificaram que todas as doses elevaram a DIVMS.

Após a abertura dos silos, observou-se redução numérica em todos os valores de DIVMS, pois, durante a ensilagem, ocorreu aumento dos teores de FDN e redução dos CNF. Fato semelhante foi constatado por Castro Neto et al. (2003), que observaram redução da digestibilidade da cana- 
Tabela 5 - Valores de CNF (\%) e de DIVMS (\%), antes da ensilagem e após a abertura dos silos, da cana-de-açúcar tratada ou não com aditivos químicos e bacterianos

Table 5 - Values of NFC and IVDMD, before ensilage and after opening of the silos, of the sugar cane treated or not with chemical additives or inoculants

\begin{tabular}{|c|c|c|c|c|c|c|c|c|}
\hline \multirow[t]{2}{*}{$\begin{array}{l}\text { Tratamento } \\
\text { Treatment }\end{array}$} & \multicolumn{4}{|c|}{$\begin{array}{l}\text { Ensilagem } \\
\text { Ensilage }\end{array}$} & \multicolumn{4}{|c|}{$\begin{array}{l}\text { Abertura } \\
\text { Silo opening }\end{array}$} \\
\hline & $\begin{array}{l}\text { Controle } \\
\text { Control }\end{array}$ & $\mathrm{PROP}^{2}$ & $\mathrm{BUCH}^{3}$ & $\begin{array}{l}\text { Média } \\
\text { Mean }\end{array}$ & $\begin{array}{l}\text { Controle } \\
\text { Control }\end{array}$ & $\mathrm{PROP}^{2}$ & $\mathrm{BUCH}^{3}$ & $\begin{array}{l}\text { Média } \\
\text { Mean }\end{array}$ \\
\hline & \multicolumn{8}{|c|}{ CNF (NFC) } \\
\hline Controle (Control) & $40,0 \mathrm{ABa}$ & $41,3 \mathrm{Aa}$ & $38,0 \mathrm{Bb}$ & $39,8 b$ & $14,9 \mathrm{Bc}$ & $17,0 \mathrm{Bc}$ & $24,9 \mathrm{Ab}$ & $18,9 a$ \\
\hline Uréia (Urea) & $29,4 \mathrm{Ab}$ & $26,7 \mathrm{Bb}$ & $29,0 \mathrm{ABc}$ & $28,4 \mathrm{c}$ & $5,1 \mathrm{Cd}$ & $11,8 \mathrm{Bd}$ & 17,6 Ac & $11,5 d$ \\
\hline Benzoato (Benzoate) & $42,3 \mathrm{ABa}$ & $43,2 \mathrm{Aa}$ & $40,0 \mathrm{ABb}$ & $41,8 \mathrm{a}$ & $21,3 \mathrm{Bb}$ & $22,4 \mathrm{Bb}$ & 30,3Аа & $24,7 b$ \\
\hline $\mathrm{NaOH}$ & $40,7 \mathrm{Ba}$ & $42,6 \mathrm{ABa}$ & $43,8 \mathrm{Aa}$ & $42,4 \mathrm{a}$ & $27,8 \mathrm{Ba}$ & $33,8 \mathrm{Aa}$ & $31,7 \mathrm{Aa}$ & $31,1 \mathrm{a}$ \\
\hline Média (Mean) & $38,1 \mathrm{~A}$ & $38,5 \mathrm{~A}$ & $37,7 \mathrm{~A}$ & 38,1 & $17,3 \mathrm{C}$ & $21,3 \mathrm{~B}$ & $26,1 \mathrm{~A}$ & 21,5 \\
\hline \multirow[t]{2}{*}{ CV (\%) } & & & & 3,20 & & & & 6,46 \\
\hline & \multicolumn{8}{|c|}{ DIVMS (DIVMS) } \\
\hline Controle (Control) & $52,6 \mathrm{Bb}$ & $57,8 \mathrm{Ab}$ & $52,7 \mathrm{Bc}$ & $54,4 \mathrm{~b}$ & $35,1 \mathrm{Bc}$ & $34,6 \mathrm{Bc}$ & $48,4 \mathrm{Ac}$ & $39,4 d$ \\
\hline Uréia (Urea) & $53,2 \mathrm{Bb}$ & $52,8 \mathrm{Bc}$ & $57,4 \mathrm{Ab}$ & $54,5 b$ & $37,7 \mathrm{Bbc}$ & $45,0 \mathrm{Ab}$ & $45,8 \mathrm{Ac}$ & $42,8 \mathrm{c}$ \\
\hline Benzoato (Benzoate) & $55,8 \mathrm{Ab}$ & $57,6 \mathrm{Ab}$ & $56,6 \mathrm{Abc}$ & $56,7 \mathrm{~b}$ & $39,7 \mathrm{Cb}$ & $45,0 \mathrm{Bb}$ & $52,3 \mathrm{Ab}$ & $45,7 b$ \\
\hline $\mathrm{NaOH}$ & $66,2 \mathrm{Aa}$ & $68,7 \mathrm{Aa}$ & $69,9 \mathrm{Aa}$ & $68,2 \mathrm{a}$ & $59,6 \mathrm{Ba}$ & $60,3 \mathrm{ABa}$ & $63,2 \mathrm{Aa}$ & $61,1 \mathrm{a}$ \\
\hline Média (Mean) & $57,0 \mathrm{~B}$ & $59,2 \mathrm{~A}$ & $59,1 \mathrm{~A}$ & 58,4 & $43,0 \mathrm{C}$ & $46,2 \mathrm{~B}$ & $52,4 \mathrm{~A}$ & 47,2 \\
\hline CV (\%) & & & & 3,25 & & & & 3,22 \\
\hline
\end{tabular}

Médias seguidas da mesma letra, maiúscula na linha e minúscula na coluna, não diferem $(P<0,05)$ pelo teste Tukey.

Means followed by the same small letter, capital in a row and small in the column, are similar $(P>0.05)$ by Tukey test.

${ }^{1} 1,5 \%$ de uréia; $0,1 \%$ de benzoato de sódio e $1 \%$ de hidróxido de sódio em relação à matéria verde.

1 . 1 \% of urea; $0.1 \%$ of sodium benzoate, and $1 \%$ of sodium hidroxide expressed in a fresh basis.

2 Propionibacterium acidipropionici + Lactobacillus plantarum; ${ }^{3}$ Lactobacillus buchneri.

de-açúcar após a ensilagem em todos os tratamentos aplicados. As silagens com os maiores valores de DIVMS apresentaram também os maiores valores de CNF e os menores de FDN após a abertura. A cana-de-açúcar possui duas frações predominantes em sua constituição, CNF e FDN, que representam $90 \%$ da constituição dessa forragem. A fração FDN é caracterizada por baixa digestibilidade, o que foi constatado por Corrêa et al. (2003), que avaliaram a digestibilidade in vivo de dietas com cana-de-açúcar para vacas com produção média de 31,9 kg de leite/dia e observaram digestibilidade da FDN de $23,1 \%$, enquanto a dieta com silagem de milho apresentou digestibilidade de $42 \%$. Conseqüentemente, a redução da DIVMS das silagens de cana-de-açúcar pode ser atribuída ao incremento da FDN, que apresenta baixa digestibilidade, como constatado por Côrrea et al. (2003).

Durante a ensilagem da cana-de-açúcar, observa-se atividade expressiva de leveduras (Alli et al., 1983; Pedroso et al., 2005). Essas leveduras consomem açúcares solúveis e promovem redução da MS e da DIVMS. No entanto, a avaliação simplista das características químicobromatológicas sem as devidas correções das perdas quantitativas pode subestimar a verdadeira extensão das perdas qualitativas. As silagens tratadas com BUCH, em comparação às tratadas com $\mathrm{NaOH}$ ou com aditivos químicos, apresentaram as maiores recuperações da CNF e MSDV, observando-se ainda efeito sinérgico entre BUCH e $\mathrm{NaOH}$. Maiores recuperações de MSDV significam manutenção do valor nutritivo da silagem em relação ao da forragem original.

A maior RMSD nas silagens tratadas com L. buchneri pode ser atribuída à produção de ácido acético por esse microrganismo (Danner et al., 2003). Esse ácido, em pH inferior ao seu $\mathrm{pK}_{\mathrm{a}}(4,73)$, mantém-se na forma não dissociada, de modo que a entrada do ácido pela membrana (permeável a esse ácido) dos microrganismos é realizada via transporte passivo. Dentro das células, o ácido é dissociado $\left(\mathrm{RCOO}^{-} \mathrm{e} \mathrm{H}^{+}\right)$, pois o $\mathrm{pH}$ interno do microrganismo é de 7,0 (superior ao $\mathrm{pK}_{\mathrm{a}}$ ), liberando íons $\mathrm{H}^{+}$e provocando rápida redução do $\mathrm{pH}$ intracelular. Para elevar novamente o pH, o microrganismo expulsa os íons $\mathrm{H}^{+}$, o que implica gasto de energia, pois trata-se de um processo de transporte ativo, retardando o crescimento e podendo causar a morte celular (McDonald et al., 1991).

$\mathrm{Na}$ associação de $\mathrm{NaOH}$ e BUCH, a maior RMSD pode ser atribuída ao fato de que a manutenção do $\mathrm{pH}$ em valores mais altos durante a fermentação pode ter estimulado o crescimento do L. buchneri e aumentado a síntese de ácido acético, que tem como função nessas silagens inibir o crescimento de leveduras, o que é fundamental, pois as leveduras são os principais responsáveis pela produção de $\mathrm{CO}_{2}$ durante a fermentação dos carboidratos solúveis a etanol. Outro efeito que pode ter propiciado a elevação da 
Tabela 6 - Recuperações dos CNF (Rec CNF) e da MS digestível verdadeira (Rec MSDV), em porcentagem da fração ensilada, da canade-açúcar tratada ou não com aditivos químicos e bacterianos

Table 6 - $\quad$ NFC recovery (Rec CNF) and true digestible DM recovery (Rec MSDV) as percentage of the ensiled fraction of the sugar cane treated or not with chemical additives or inoculants

\begin{tabular}{|c|c|c|c|c|c|c|c|c|}
\hline \multirow{2}{*}{$\begin{array}{l}\text { Tratamento }{ }^{1} \\
\text { Treatment }\end{array}$} & \multicolumn{4}{|c|}{ Rec CNF (\%) } & \multicolumn{4}{|c|}{ Rec MSDV (\%) } \\
\hline & $\begin{array}{c}\text { Controle } \\
\text { Control }\end{array}$ & $\mathrm{PROP}^{2}$ & $\mathrm{BUCH}^{3}$ & $\begin{array}{l}\text { Média } \\
\text { Mean }\end{array}$ & $\begin{array}{c}\text { Controle } \\
\text { Control }\end{array}$ & $\mathrm{PROP}^{2}$ & $\mathrm{BUCH}^{3}$ & $\begin{array}{c}\text { Média } \\
\text { Mean }\end{array}$ \\
\hline Controle (Control) & $25,2 \mathrm{Bc}$ & $27,2 \mathrm{Bc}$ & $53,1 \mathrm{Ab}$ & $35,2 c$ & $45,0 \mathrm{Bc}$ & $39,8 \mathrm{Bc}$ & $74,3 \mathrm{Ab}$ & $53,0 \mathrm{~d}$ \\
\hline Uréia (Urea) & $12,6 \mathrm{Cd}$ & 33,3Bbc & $48,4 \mathrm{Ab}$ & $31,4 \mathrm{c}$ & $51,6 \mathrm{Bb}$ & $64,0 \mathrm{Ab}$ & $63,7 \mathrm{Ac}$ & $59,8 c$ \\
\hline Benzoato (Benzoate) & $37,7 \mathrm{Bb}$ & $38,9 \mathrm{Bb}$ & $66,1 \mathrm{Aa}$ & $47,6 b$ & $53,2 \mathrm{Bb}$ & $58,5 \mathrm{Bb}$ & $80,6 \mathrm{Aab}$ & $64,1 b$ \\
\hline $\mathrm{NaOH}$ & $52,0 \mathrm{Ba}$ & $68,6 \mathrm{Aa}$ & $67,7 \mathrm{Aa}$ & $62,8 a$ & $68,5 \mathrm{Ca}$ & $76,0 \mathrm{Ba}$ & $84,8 \mathrm{Aa}$ & $76,4 a$ \\
\hline Média (Mean) & $31,9 \mathrm{C}$ & $42,0 \mathrm{~B}$ & $58,8 \mathrm{~A}$ & 44,2 & $54,6 \mathrm{C}$ & $59,6 \mathrm{~B}$ & $75,9 \mathrm{~A}$ & 63,3 \\
\hline CV (\%) & & & & 7,22 & & & & 4,59 \\
\hline
\end{tabular}

Médias seguidas da mesma letra, maiúscula na linha e minúscula na coluna, não diferem $(P<0,05)$ pelo teste Tukey.

Means followed by the same small letter, capital in a row and small in the column, are similar $(P>0.05)$ by Tukey test.

${ }_{1}^{1} 1,5 \%$ de uréia; $0,1 \%$ de benzoato de sódio e $1 \%$ de hidróxido de sódio em relação à matéria verde.

$11.5 \%$ of urea; $0.1 \%$ of sodium benzoate, and $1 \%$ of sodium hidroxide expressed in a fresh basis.

2 Propionibacterium acidipropionici + Lactobacillus plantarum; ${ }^{3}$ Lactobacillus buchneri.

RMSD é a inclusão de substâncias alcalinas que estimulam a proliferação de bactérias homofermentativas, que, por sua vez aumentam a produção de ácido lático, especialmente na ensilagem da cana-de-açúcar (Nieblas et al., 1982). O ácido lático é considerado substrato para o L. buchneri produzir ácido acético (Oude Elferink et al., 2001) e 1,2-propanodiol, que também é um composto com efeito inibitório sobre o crescimento de leveduras (Oude Elferink et al., 2001).

Após a abertura dos silos e com a exposição da massa ensilada aos efeitos do oxigênio do ambiente, um novo quadro de alterações microbiológicas, químicas e oxidativas se instalou. Alguns produtos da fermentação passaram a ser substrato e microrganismos outrora latentes começaram a se desenvolver.

Na Tabela 7 encontram-se os teores de MS das silagens após cinco dias de exposição aeróbia. Não houve diferença $(\mathrm{P}>0,05)$ entre os aditivos químicos, contudo, as silagens com inoculantes (PROP e BUCH) e controle diferiram quanto à inoculação. A elevação dos teores de MS durante a exposição aeróbia foi ocasionada pela perda de água para o ambiente.

Os teores de PB nas silagens produzidas sem uréia aumentaram em relação àqueles observados após a abertura dos silos (Tabelas 3 e 8), o que, possivelmente, foi conseqüência das perdas de MS (carboidratos solúveis) durante a exposição aeróbia. Segundo Pitt et al. (1991), os carboidratos solúveis e o ácido lático são os principais substratos consumidos nessa fase. Conseqüentemente, houve concentração dos teores de $\mathrm{PB}$ e não síntese dessa fração no período posterior à abertura. Contudo, nas silagens tratadas com uréia, houve redução dos teores de PB (Tabelas 3 e 8), o que pode ser resultado da perda de amônia por volatilização durante a exposição aeróbia.
Tabela 7 - Teores de MS (\%) após cinco dias de exposição aeróbia da cana-de-açúcar tratada ou não com aditivos químicos e bacterianos

Table 7 - DM concentration of the sugar cane treated or not with chemical additives or inoculants after five days of air exposure

\begin{tabular}{lcccc}
\hline $\begin{array}{l}\text { Tratamento } \\
\text { Treatment }\end{array}$ & \multicolumn{4}{c}{$\begin{array}{c}\text { MS (\%) } \\
\% \text { DM }\end{array}$} \\
\cline { 2 - 5 } & $\begin{array}{c}\text { Controle } \\
\text { Control }\end{array}$ & PROP $^{2}$ & BUCH $^{3}$ & $\begin{array}{c}\text { Média } \\
\text { Mean }\end{array}$ \\
\hline Controle (Control) & 39,3 & 37,6 & 37,1 & $38,0 \mathrm{a}$ \\
Uréia (Urea) & 44,4 & 36,6 & 36,1 & $39,0 \mathrm{a}$ \\
Benzoato (Benzoate) & 40,4 & 38,4 & 41,6 & $40,1 \mathrm{a}$ \\
NaOH & 44,4 & 35,5 & 36,6 & $38,8 \mathrm{a}$ \\
Média (Mean) & $42,1 \mathrm{~A}$ & $37,0 \mathrm{~B}$ & $37,8 \mathrm{~B}$ & 39,0 \\
CV (\%) & & & & 9,08 \\
\hline
\end{tabular}

Médias seguidas da mesma letra, maiúscula na linha e minúscula na coluna não diferem $(P<0,05)$ pelo teste Tukey.

Means followed by the same small letter, capital in a row and small in the column, are similar $(P>0.05)$ by Tukey test.

${ }^{1} 1,5 \%$ de uréia; $0,1 \%$ de benzoato de sódio e $1 \%$ de hidróxido de sódio em relação à matéria verde.

1 1.5\% of urea; $0.1 \%$ of sodium benzoate, and $1 \%$ of sodium hidroxide expressed in a fresh basis.

2 Propionibacterium acidipropionici + Lactobacillus plantarum; ${ }^{3}$ Lactobacillus buchneri.

Como consta na Tabela 8, os teores de NIDN reduziram nas silagens produzidas sem uréia e aumentaram naquelas tratadas com uréia. Esse efeito provavelmente está associado às alterações nos teores de $\mathrm{PB}$, pois o NIDN é apresentado como porcentagem do nitrogênio total. Outra possível explicação para redução nos teores de NIDN foi exposta por Bernardes (2003). Segundo esse autor, a fração B3 pode ser utilizada como substrato pelos microrganismos deterioradores, pois representa a diferença do nitrogênio retido na FDN e do nitrogênio retido na FDA. Provavelmente, esse processo proporcionou as reduções dos teores de NIDN durante a exposição aeróbia das silagens de cana-de-açúcar avaliadas. 
Tabela 8 - Teores de PB (\%), NIDN/N, FDN (\%), FDA (\%) e lignina (\%) e digestibilidade in vitro da MS (DIVMS\%) após cinco dias de exposição aeróbia da cana-de-açúcar tratada ou não com aditivos químicos e bacterianos na ensilagem da cana-de-açúcar

Table 8 - $\quad C P(C P \%), N-N D F, N D F, A D F$, lignin, and true in vitro DM digestibility of the sugar cane treated or not with chemical additives or inoculants after five days of air exposure

\begin{tabular}{|c|c|c|c|c|c|c|c|c|}
\hline $\begin{array}{l}\text { Tratamento }{ }^{1} \\
\text { Treatment }\end{array}$ & $\begin{array}{l}\text { Controle } \\
\text { Control }\end{array}$ & $\mathrm{PROP}^{2}$ & $\mathrm{BUCH}^{3}$ & $\begin{array}{l}\text { Média } \\
\text { Mean }\end{array}$ & $\begin{array}{c}\text { Controle } \\
\text { Control }\end{array}$ & $\mathrm{PROP}^{2}$ & $\mathrm{BUCH}^{3}$ & $\begin{array}{l}\text { Média } \\
\text { Mean }\end{array}$ \\
\hline & \multicolumn{4}{|c|}{$\mathrm{PB}(C P)$} & \multicolumn{4}{|c|}{ N-FDN (\% do $\mathrm{N}$ total) ( $N-N D F, \%$ of total $N)$} \\
\hline Controle (Control) & $3,4 \mathrm{Ab}$ & $2,8 \mathrm{Ab}$ & $2,7 \mathrm{Ab}$ & $3,0 b$ & $29,8 \mathrm{ABb}$ & $33,5 \mathrm{Ab}$ & $24,8 \mathrm{Bb}$ & $29,4 b$ \\
\hline Uréia (Urea) & $8,8 \mathrm{Ba}$ & 9,9Аа & $8,1 \mathrm{Ba}$ & $8,9 a$ & $17,1 \mathrm{Ac}$ & $15,8 \mathrm{Ad}$ & $12,3 \mathrm{Bc}$ & $15,1 \mathrm{~d}$ \\
\hline Benzoato (Benzoate) & $2,7 \mathrm{Ab}$ & $3,0 \mathrm{Ab}$ & $2,6 \mathrm{Ab}$ & $2,8 \mathrm{bc}$ & $27,4 \mathrm{Ab}$ & $26,0 \mathrm{Ac}$ & $22,7 \mathrm{Ab}$ & $25,3 c$ \\
\hline $\mathrm{NaOH}$ & $2,9 \mathrm{Ab}$ & $2,2 \mathrm{Ab}$ & $2,1 \mathrm{Ab}$ & $2,4 \mathrm{c}$ & $35,8 \mathrm{Ba}$ & $45,0 \mathrm{Aa}$ & $46,7 \mathrm{Aa}$ & $42,5 \mathrm{a}$ \\
\hline Média (Mean) & $4,4 \mathrm{~A}$ & $4,5 \mathrm{~A}$ & $3,9 \mathrm{~B}$ & 4,3 & $27,5 \mathrm{AB}$ & $30,1 \mathrm{~A}$ & $26,6 \mathrm{~B}$ & 28,1 \\
\hline \multirow[t]{2}{*}{ CV (\%) } & & & & 9,43 & & & & 9,30 \\
\hline & \multicolumn{4}{|c|}{ FDN $(N D F)$} & \multicolumn{4}{|c|}{ FDA $(A D F)$} \\
\hline Controle (Control) & 81,3 & 80,3 & 68,5 & $76,7 a$ & $67,8 \mathrm{Aa}$ & $66,9 \mathrm{Aa}$ & $55,9 \mathrm{Ba}$ & $63,5 \mathrm{a}$ \\
\hline Uréia (Urea) & 80,0 & 77,1 & 69,4 & $75,5 \mathrm{ab}$ & $62,5 \mathrm{Ab}$ & $62,1 \mathrm{Ab}$ & $56,4 \mathrm{Ba}$ & $60,3 b$ \\
\hline Benzoato (Benzoate) & 71,4 & 70,1 & 64,1 & $68,5 b$ & $61,2 \mathrm{Ab}$ & $58,7 \mathrm{Ab}$ & $45,7 \mathrm{Bb}$ & $55,2 \mathrm{c}$ \\
\hline $\mathrm{NaOH}$ & 61,6 & 58,7 & 58,9 & $59,8 c$ & $52,7 \mathrm{Ac}$ & $50,6 \mathrm{Ac}$ & $43,5 \mathrm{Bb}$ & $49,0 \mathrm{~d}$ \\
\hline Média (Mean) & $73,6 \mathrm{~A}$ & $71,5 \mathrm{AB}$ & $65,2 \mathrm{~B}$ & 70,10 & $61,0 \mathrm{~A}$ & $59,6 \mathrm{~A}$ & $50,4 \mathrm{~B}$ & 57,0 \\
\hline \multirow[t]{2}{*}{ CV (\%) } & & & & 7,99 & & & & 3,26 \\
\hline & \multicolumn{4}{|c|}{ Lignina (Lignin) } & \multicolumn{4}{|c|}{ DIVMS (\%) (IVVDM, \%) } \\
\hline Controle (Control) & 13,1 & 12,0 & 10,3 & $11,8 \mathrm{a}$ & $33,7 \mathrm{Cc}$ & $37,9 \mathrm{Bc}$ & $48,2 \mathrm{Ab}$ & $39,9 \mathrm{C}$ \\
\hline Uréia (Urea) & 11,7 & 10,5 & 9,9 & $10,7 b$ & $41,0 \mathrm{Ab}$ & $40,9 \mathrm{Abc}$ & $43,6 \mathrm{Ac}$ & $41,8 \mathrm{C}$ \\
\hline Benzoato (Benzoate) & 9,8 & 10,2 & 7,4 & $9,1 \mathrm{c}$ & 43,9Bb & $43,3 \mathrm{Bb}$ & 48,3Ab & $45,2 \mathrm{~B}$ \\
\hline $\mathrm{NaOH}$ & 8,8 & 8,0 & 7,3 & $8,0 \mathrm{~d}$ & $60,6 \mathrm{Ba}$ & $65,0 \mathrm{Aa}$ & $63,0 \mathrm{ABa}$ & $62,9 \mathrm{~A}$ \\
\hline Média (Mean) & $10,8 \mathrm{~A}$ & $10,2 \mathrm{~A}$ & $8,7 \mathrm{~B}$ & 9,9 & $44,8 \mathrm{C}$ & $46,8 \mathrm{~B}$ & $50,8 \mathrm{~A}$ & 47,4 \\
\hline CV (\%) & & & & 7,65 & & & & 3,51 \\
\hline
\end{tabular}

Médias seguidas da mesma letra, maiúscula na linha e minúscula na coluna, não diferem $(P<0,05)$ pelo teste Tukey.

Means followed by the same small letter, capital in a row and small in the column, are similar $(P>0.05)$ by Tukey test.

1 1,5\% de uréia; $0,1 \%$ de benzoato de sódio e $1 \%$ de hidróxido de sódio em relação à matéria verde.

$1.5 \%$ of urea; $0.1 \%$ of sodium benzoate, and $1 \%$ of sodium hidroxide expressed in a fresh basis.

2 Propionibacterium acidipropionici + Lactobacillus plantarum; ${ }^{3}$ Lactobacillus buchneri.

Os teores de FDN, FDA e lignina apresentaram a mesma tendência de alterações com a exposição aeróbia (Tabelas 4 e 8). De modo geral, as silagens apresentaram acréscimo numérico nestes parâmetros após a exposição aeróbia. Durante o processo de exposição aeróbia, pode ocorrer redução de carboidratos solúveis residuais e ácido lático (Ranjit \& Kung Jr., 2000), propiciando incrementos percentuais nos teores das frações relacionadas à fibra (FDN, FDA e LIG).

Os valores de DIVMS tiveram aumento de até 4,2 unidades percentuais nas silagens tratadas somente com benzoato e redução de até 4,0 unidades percentuais nas silagens tratadas com benzoato e inoculadas com BUCH. As variações nos teores de hemicelulose, calculadas como a diferença da FDN e da FDA após a exposição aeróbia subtraída do teor de hemicelulose após a abertura, apresentaram os seguintes resultados: -15,6 e 6,4 unidades percentuais nas silagens tratadas somente com benzoato e nas silagens tratadas com benzoato e inoculadas com BUCH, respectivamente. Provavelmente, ocorreu degradação e conseqüente solubilização da hemicelulose nas silagens tratadas somente com benzoato, elevando a DIVMS dessas silagens. Todavia, nas silagens tratadas com benzoato e inoculadas com BUCH, esse fato não foi constatado e, conseqüentemente, houve redução da DIVMS, pois, no processo de deterioração aeróbia, ocorre consumo de frações digestíveis pelos microrganismos, acarretando redução da digestibilidade e do conteúdo de energia (Jobim \& Gonçalves, 2003).

\section{Conclusões}

Em virtude das grandes alterações no valor nutritivo da cana-de-açúcar, é necessária a presença de algum aditivo no processo de ensilagem. Como aditivo químico, destaca-se o hidróxido de sódio e, como inoculante bacteriano, o L. buchneri e as associações de hidróxido de sódio e P. acidipropionici ou L. buchneri, pois esses aditivos propiciaram as menores alterações químicas nas variáveis avaliadas durante a fermentação, principalmente as decorrentes das recuperações de CNF e de MS digestível verdadeira. 
Durante a exposição aeróbia, o L. buchneri e o $\mathrm{NaOH}$ destacaram-se principalmente pela atuação sobre as características relacionadas à fibra (FDN, FDA e lignina) e sobre a manutenção da DIVMS.

\section{Literatura Citada}

ALLI, I.; FAIRBAIRN, R.; BAKER, B.E. et al. The effects of ammonia on the fermentation of chopped sugarcane. Animal Feed Science and Technology, v.9, p.291-299, 1983.

ALVAREZ, F.J.; PRESTON, T.R. Ammonia/molasses and urea/ molasses as additives for ensiled sugar cane. Tropical Animal Production, v.1, p.98-104, 1976.

BERNARDES, T.F. Características fermentativas, microbiológicas e químicas do capim-Marandu (Brachiaria brizantha (Hoschst ex. A. Rich) Stapf cv. Marandu) ensilado com polpa cítrica peletizada. Jaboticabal: Universidade Estadual Paulista, 2003. 118p. Dissertação (Mestrado em Zootecnia) Universidade Estadual Paulista, 2003.

CASTRO NETO, A.; FERREIRA, D.A.; MOLINA, L.R. et al. Avaliação de silagens de cana-de-açúcar submetidas a diferentes tratamentos: II. Proteína bruta, frações fibrosas e digestibilidade “in vitro" da matéria seca. In: REUNIÃO ANUAL DA SOCIEDADE BRASILEIRA DE ZOOTECNIA, 40., 2003, Santa Maria. Anais... Santa Maria: Sociedade Brasileira de Zootecnia, 2003. (CD-ROM).

CORREAA, C.E.S.; PEREIRA, M.N.; OLIVEIRA, S.G. et al. Performance of Holstein cows fed sugarcane or corn silages of different grain textures. Scientia Agricola, v.60, p.221-229, 2003.

DANNER, H.; HOLZER, M.; MAYRHUBER, E. et al. Acetic acid increases stability of silage under aerobic conditions. Applied and Environmental Microbiology, v.69, p.562-567, 2003.

EVANGELISTA, A.R.; LIMA, J.A.; SIQUEIRA, G.R. et al. Perfil de fermentação da silagem de cana-de-açúcar (Saccharum officinarum L.). In: REUNIÃO ANUAL DA SOCIEDADE BRASILEIRA DE ZOOTECNIA, 40., 2003, Santa Maria. Anais... Santa Maria: Sociedade Brasileira de Zootecnia, 2003. (CD-ROM).

FILYA, I.; SUCU, E.; KARABULUT, A. The effect of Propionibacterium acidipropionici, with or without Lactobacillus plantarum, on the fermentation and aerobic stability of wheat, sorghum and maize silages. Journal Applied Microbiology, v.97, p.818-821, 2004

JOBIM, C.C.; GONÇALVES, G.D. Microbiologia de forragens conservadas. In: REIS, R.A.; BERNARDES, T.F.; SIQUEIRA, G.R. et al. (Eds.) Volumosos na produção de ruminantes: valor alimentício de forragens. Jaboticabal: Funep, 2003. p.1-26.

KUNG JR., L.; STOKES, M.R.; LIN, C.J. Silage additives. In: BUXTON, D.R.; MUCK, R.E.; HARRISON, J.H. (Eds.) Silage science and technology. Madison: American Society of Agronomy, Crop Science Society of America, Soil Science Society of America, 2003. p.251-304.
McDOnAlD, P.; Henderson, A.R.; HERON, S.J.E. The biochemistry of silage. 2.ed. Marlow: Chalcomb Publications, 1991. 340p.

NIEBLAS, T.D.; SHIMADA, A.S.; PALACIOS, J.T. Manipulación de la fermentación en ensilaje de caña de azúcar y valor alimenticio para borregos. 3. Digestibilidad aparente. Veterinaria México, v.13, p.23-26, 1982.

NUSSIO, L.G.; SCHIMDT, P. Tecnologia de produção e valor alimentício de silagens de cana-de-açúcar. In: SIMPÓSIO SOBRE PRODUÇÃO E UTILIZAÇÃO DE FORRAGENS CONSERVADAS, 2., 2004, Maringá. Anais... Maringá: UEM/ CCA/DZO, 2004. p.1-33.

OUDE ELFERINK, S.J.W.H.; KROONEMAN, J.; GOTTSCHAL, J.C. et al. Anaerobic conversion of lactic acid to acetic acid and 1,2-propanediol by Lactobacillus buchneri. Applied and Environmental Microbiology, v.67, p.125-132, 2001.

PEDROSO, A.F.; NUSSIO, L.G.; PAZIANI, S.F. et al. Fermentation and epiphytic microflora dynamics in sugar cane silage. Scientia Agricola, v.62, p.427-432, 2005.

PIRES, A.J.V.; REIS, R.A.; CARVALHO, G.G.P. et al. Bagaço de cana-de-açúcar tratado com hidróxido de sódio. Revista Brasileira de Zootecnia, v.35, p.953-957, 2006.

PITT, R.E.; MUCK, R.E.; PICKERING, N.B. A model of aerobic fungal growth in silage. 2. Aerobic stability. Grass and Forage Science, v.46, p.301-312, 1991.

RANJIT, N.K.; KUNG JR., L. The effect of Lactobacillus buchneri, Lactobacillus plantarum, or a chemical preservation on fermentation and aerobic stability of corn silage. Journal of Dairy Science, v.83, p.526-535, 2000.

ROCHA JR., V.R.; VALADARES FILHO, S.C.; BORGES, A.M. et al. Determinação do valor energético de alimentos para ruminantes pelo sistema de equações. Revista Brasileira de Zootecnia, v.32, p.473-479, 2003.

SILVA, D.J.; QUEIROZ, A.C. Análise de alimentos: métodos químicos e biológicos. 3.ed. Viçosa, MG: Editora UFV, 2002. 235p.

Van SOEST, P. Nutritional ecology of the ruminant. 2.ed. Ithaca: Cornell University Press, 1994. 476p.

Van SOEST, P.J.; ROBERTSON, J.B.; LEWIS, B.A. Methods for dietary fiber, neutral detergent fiber and nonstarch polysaccharides in relation to animal nutrition. Journal of Dairy Science, v.74, p.3583-3597, 1991.

WOOLFORD, M.K. Microbiological screening of food preservatives, cold sterilants and specific antimicrobial agents as potential silage additives. Journal of the Science of Food and Agricultural, v.26, p.229-237, 1975. 